\title{
A Study Of Correlation Between Central Corneal Thickness And Intra Ocular Pressure Measurement Using Goldmann Applanation Tonometer And Rebound Tonometer
}

\author{
Dr Bindu Malini ${ }^{1,}$ Dr Rajendra R. ${ }^{2}$, Dr Anita G ${ }^{3}$, Dr Rohit Rao ${ }^{4}$ \\ ${ }^{1}$ (Ophthalmology Department, JSS Medical College, India) \\ ${ }^{2}$ (Ophthalmology Department, JSS Medical College, India) \\ ${ }^{3}$ (Ophthalmology Department, JSS Medical College, India) \\ ${ }^{4}$ (Ophthalmology Department, JSS Medical College, India)
}

\begin{abstract}
Introduction: The purpose of this study was to note the influence of central corneal thickness on the intraocular pressure measurementand to compare rebound tonometer and Goldmannapplanation tonometerduring the recent 2 years in Ophthalmology OPD of JSS Hospital. Objectives:

- To compare rebound tonometer and Goldmannapplanation tonometer

- Influence of central corneal thickness on the intraocular pressure measurement

Methodology:A total of 409 patients inclusive of normal controls, proven glaucoma cases and glaucoma suspects were evaluated prospectively, from October 2010 to June 2012. They were studied for their presentation, clinical features and intraocular pressure readings and central corneal thickness were measured. Results: A total of 797 eyes were included in the study. 199 eyes were examined under glaucoma group, out of which 33 patients had closed angle glaucoma and 166 had open angle glaucoma.

Majority of the patients in the study population were males in both control and glaucoma group (54.03\%). In the glaucoma group consisting of proven glaucoma cases and glaucoma suspects majority had open angle (83.41\%). More number of participants belonged to the age group of 40-50 years (45\%). The highest mean GAT, RBT and CCT values were obtained for the age group between 61-70 years. The minimum intraocular pressure value obtained using rebound tonometer was $9 \mathrm{~mm} \mathrm{Hg}$ and maximum value was $56 \mathrm{~mm} \mathrm{Hg}$ in the entire study group. The minimum intraocular pressure value obtained using Goldmannapplanation tonometer was $8 \mathrm{~mm} \mathrm{Hg}$ and maximum value was $50 \mathrm{~mm} \mathrm{Hg}$ in the entire study group. The minimum value for central corneal thickness was $443 \mu \mathrm{m}$ and maximum value was $675 \mu \mathrm{m}$ for the entire study group. For the entire study group intraocular pressure values obtained by rebound tonometer $(14.81 \pm 2.81 \mathrm{~mm} \mathrm{Hg}$ in normal group and $20.55 \pm 8.74 \mathrm{~mm} \mathrm{Hg}$ In glaucoma group) was more than Goldmannapplanation tonometer (14.47 $\pm 2.98 \mathrm{~mm}$ hg and $19.88 \pm 8.74 \mathrm{~mm} \mathrm{Hg}$ ). For central corneal thickness $\leq 530 \mu \mathrm{m}$, Rebound tonometer values were more than Goldmannapplanation tonometer values in both control and control group. The mean difference was 0.4 $3.9 \mathrm{~mm} \mathrm{Hg}$ and $0.3 \mathrm{~mm} \mathrm{Hg}$ which was not statistically significant ( $p$ values- 0.74, 0.792). For central corneal thickness $\geq 531 \mu \mathrm{m}$, Rebound tonometer values were less than Goldmannapplanation tonometer values in both control and control group. The mean difference was $0.0811 \mathrm{~mm} \mathrm{Hg}$ and $0.96 \mathrm{~mm} \mathrm{Hg}$ which was not statistically significant ( $p$ values- 0.811,0.93). At higher corneal thickness, Goldmannapplanation tonometer gave higher values than rebound tonometer but the difference was not statistically significant. As the central corneal thickness increased the intraocular pressure value recorded by both the tonometers increased.

Conclusion:Central corneal thickness can influence the intraocular pressure recordings of both rebound tonometer and Goldmannapplanation tonometer and thicker corneas yield higher intraocular pressure values. Therefore correction for central corneal thickness will provide a more accurate IOP reading and aid in the proper management of glaucoma cases. The Rebound tonometer gave higher readings in comparison to Goldmannapplanation tonometer in thinner corneas and lesser readings in thicker corneas. There was no statistically significant difference between the two tonometers and they showed good correlation in relation to the central corneal thickness.
\end{abstract}

Keywords : Central corneal thickness, Goldmannapplanation tonometer, Rebound tonometer

\section{INTRODUCTION}

Glaucoma is one of the leading causes for blindness in the world. It is an optic neuropathy with characteristic appearance of optic disc and specific pattern of visual field defects associated frequently but not invariably with raised intraocular pressure 
The important risk factors of glaucoma include intraocular pressure, heredity, myopia, race etc. But intraocular pressure is the most important factor as it is the only one which we can measure and modulate till date.

Goldmann Applanation tonometer is considered as the gold standard for the measurement of intraocular pressure. But the accuracy of measurement has limitations as it is influenced by a number of variables like axial length, corneal curvature, corneal rigidity, and corneal thickness. Goldmann and Schimdt believed that the central corneal thickness was very similar among individuals in the normal population. However they acknowledged that when large variations in central corneal thickness occur, the accuracy of Goldmann tonometer can be affected. Corneas that were thicker than the normal would require greater force to flatten and thinner corneas would require less. This meant that thicker corneas yielded an overestimation of intraocular pressure, whereas thinner corneas resulted in underestimation ${ }^{1}$.

In the 1970s, Ehlers et al performed a number of studies assessing the effect of CCT on IOP. They cannulated 29 otherwise normal eyes undergoing cataract surgery and correlated corneal thickness with the errors of GAT. They found that GAT most accurately reflected "true" intracameral IOP when CCT was $520 \mu \mathrm{m}$ and the deviation from this value resulted in under- or overestimation of IOP. Patients with ocular hypertension have

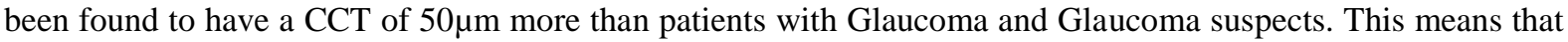
many individuals have been falsely labeled as having ocular hypertension, when in fact they have normal IOP once CCT is taken into consideration. ${ }^{1,2}$.

Over the years, several new instruments have been developed with the aim of determining IOP as precisely as possible. Among the most recent of these are the rebound tonometer (RBT; ICare, Tiolat Oy, Helsinki, Finland) and the Dynamic Contour, or Pascal, tonometer (DCT; SMT Swiss Microtechnology AG, Port, Switzerland).

Rebound tonometry had been used mainly in experimental models of glaucoma for noninvasive pressure measurements in animals ${ }^{3}$. This method has provided good results in terms of ease of use and the precision and reproducibility of marketing of a handheld tonometer, which also has been reported recently to offer reproducible IOP measurements in humans. Rebound tonometry is based on bringing a magnetized probe into contact with the eye and detecting the deceleration caused by the eye on the probe with a sensing coil. The motion parameters of the probe vary according to eye pressure and can be used to determine IOP.

The current study focuses on the influence of central corneal thickness on tonometric measurements on Goldmann applanation tonometer and rebound tonometer and also how well the two tonometers correlate with each other and whether the reproduciblity of rebound tonometer is similar to the Goldmann applanation tonometer.

\section{Material And Methods}

Mysore.

Study Setting: This study was carried out in the Department of Ophthalmology, J.S.S. Hospital,

Source: Subjects of the study were the patients visiting the outpatient department. A total of 409 patients were included in the study out of which 101 patients diagnosed of Glaucoma were included.

Study Design: It is a 2 years prospective study.

Study period: The study was carried out from October 2010 to June 2012. Patients satisfying the following criteria were included in the study.

\section{Inclusion criteria:}

1. Patients aged 40 years and above

2. Patients diagnosed of primary Glaucoma and Glaucoma suspects

3. Normal patients

\section{Exclusion criteria:}

1. Patients below 40 years of age

2. Corneal pathology

3. History of previous intraocular surgeries

4. Corneal surgeries

5. Prolonged contact lens wearers

6. Corneal dystrophies, ectatic conditions and degenerations

7. Secondary glaucomas

\section{Method of Collection of Data:}

Patients satisfying the above criteria were included in the study. Patient was explained about the study and a written consent was taken. Using a proforma details were collected regarding the name, age, sex, presenting complaints and duration, associated systemic disorders and drug history if any. Patient was subjected 
to a preliminary slit lamp examination and fundoscopy and best corrected visual acuity was recorded. Then the IOP measurements were taken using RBT and GAT and central corneal thickness was measured using ultrasonic pachymetry. In cases of glaucoma and glaucoma suspects additional investigations like gonioscopy using Goldmann 3 mirror gonio lens and visual field analysis with Humphrey field analyzer were done.

\section{Measurement of intraocular ocular pressure}

Using Goldmann Applanation Tonometer - patient is made to sit comfortably on the slit lamp chair. A drop of $4 \%$ Xylocaine is instilled into the lower fornix. The precorneal tear film is stained with fluorescien strip and the tonometer probe is brought into contact with the cornea. Cobalt blue light is focused on the probe perpendicular to the tonometer. The reading is then recorded.

\section{Using Rebound tonometer}

Patient is made to sit. Rebound tonometer with plastic probe loaded is placed at a distance of $8 \mathrm{~mm}$ in front of the eye and then readings are taken as explained before.

\section{Measurement of CCT}

The measurements were performed using the Micropach - sonomed 200 pachymeter in the automatic mode, with the subject in the sitting position, while he or she fixated on a distant target. After instilling a drop of $4 \%$ xylocaine, the probe tip was held perpendicular and placed in contact with the central cornea. Five readings were obtained and an average of these readings was recorded in micrometers. The readings were taken in the right first and then in the left eye.

\section{tatistical Methods Applied \\ Descriptive statistics}

The Descriptive procedure displays univariate summary statistics for several variables in a single table and calculates standardized values. Normally distributed continuous variables were expressed as mean (range) and non-normally distributed variables were expressed as median.

\section{Frequencies}

The Frequencies procedure provides statistics and graphical displays that are useful for describing many types of variables. The Frequencies procedure is a good place to start looking at your data.

\section{Chi-square}

The Chi-Square Test procedure tabulates a variable into categories and computes a chi-square statistic. This goodness-of-fit test compares the observed and expected frequencies in each category to test either that all categories contain the same proportion of values or that each category contains a user-specified proportion of values.

Chi-square tests were employed to find out the difference between groups of frequencies obtained for the specific statements. A P value of less than 0.005 was considered statistically significant

\section{Cross tabs procedure}

The Crosstabs procedure forms two-way and multiway tables and provides a variety of tests and measures of association for two-way tables. The structure of the table and whether categories are ordered determine what test or measure to use. All the statistical methods were carried out through the SPSS for Windows (version 17.0 SPSS Inc., Chicago, IL, USA).) and Minitab (version 11.0) for windows.

\section{Observation \& Results}

This is a prospective study carried out in JSS Hospital, Mysore. This study was carried out for 2 years from October 2010 to June 2012.

A total number of 409 patients were studied. Of these, 308 presented with insignificant ophthalmic problems, headache, presbyopic errors and were referred for fundoscopy. They were included in the control group. The remaining 101 patients were proven cases of glaucoma and glaucoma suspects who were categorized as glaucoma group.

A total of 818 eyes were examined of which 3 eyes from glaucoma group and 18 eyes from control group were excluded for previous history of cataract surgery.

Therefore a total of 797 eyes were included in the study. 199 eyes were examined under glaucoma group, out of which 33 patients had closed angle glaucoma and 166 had open angle glaucoma. 
Ratio of Glaucoma cases of Open Angles to Glaucoma cases of Closed angles

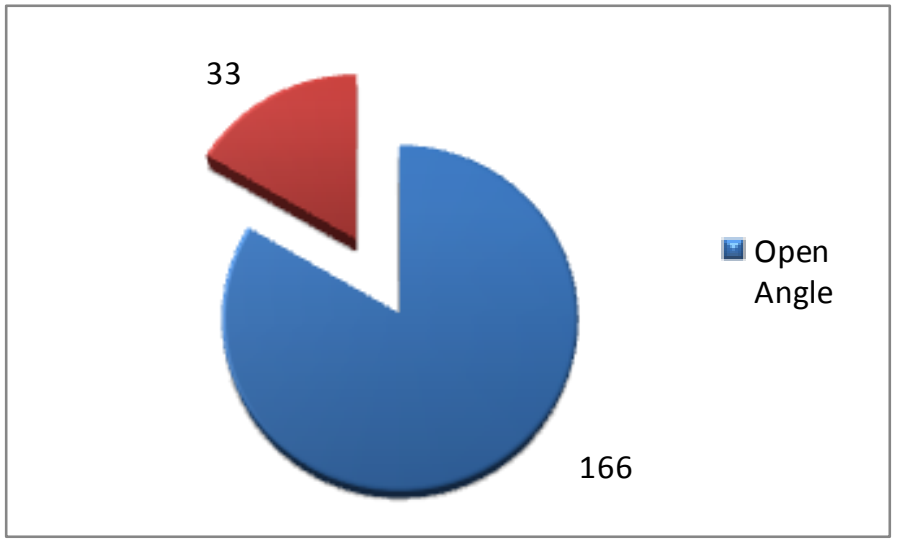

GRAPH 1: GLAUCOMA CASE DISTRIBUTION

Out 199 eyes, 166(83.41\%) patients had open angles among glaucoma and suspects and there 33 cases $(16.58 \%)$ with closed angles

Table 1: Age distribution in the study group

\begin{tabular}{|c|c|c|}
\hline Age & Frequency & Percent \\
\hline $\mathbf{4 1 - 5 0}$ & 184 & 45.0 \\
\hline $\mathbf{5 1 - 6 0}$ & 123 & 30.1 \\
\hline $\mathbf{6 1 - 7 0}$ & 72 & 17.6 \\
\hline $\mathbf{7 1 - 8 0}$ & 28 & 6.8 \\
\hline $\mathbf{8 1 - 9 0}$ & 2 & 0.5 \\
\hline
\end{tabular}

The more number of patients in the present study are from the 41-50 age group and least from 81-90 age group.

Table 2:Mean IOP values for GAT in different age groups

\begin{tabular}{|c|c|c|c|c|}
\hline Age group & N & Mean GAT & Std. dev & Std. error \\
\hline $\mathbf{4 1 - 5 0}$ & 368 & 15.4891 & 4.94712 & 0.25789 \\
\hline $\mathbf{5 1 - 6 0}$ & 246 & 15.1789 & 5.08865 & 0.32444 \\
\hline $\mathbf{6 1 - 7 0}$ & 144 & 15.7014 & 7.57164 & .63097 \\
\hline $\mathbf{7 1 - 8 0}$ & 56 & 15.5000 & 8.05210 & 1.07601 \\
\hline $\mathbf{8 1 - 9 0}$ & 4 & 13.7500 & 9.10586 & 4.55293 \\
\hline Total & 818 & 15.4254 & 5.78881 & 0.20240 \\
\hline
\end{tabular}

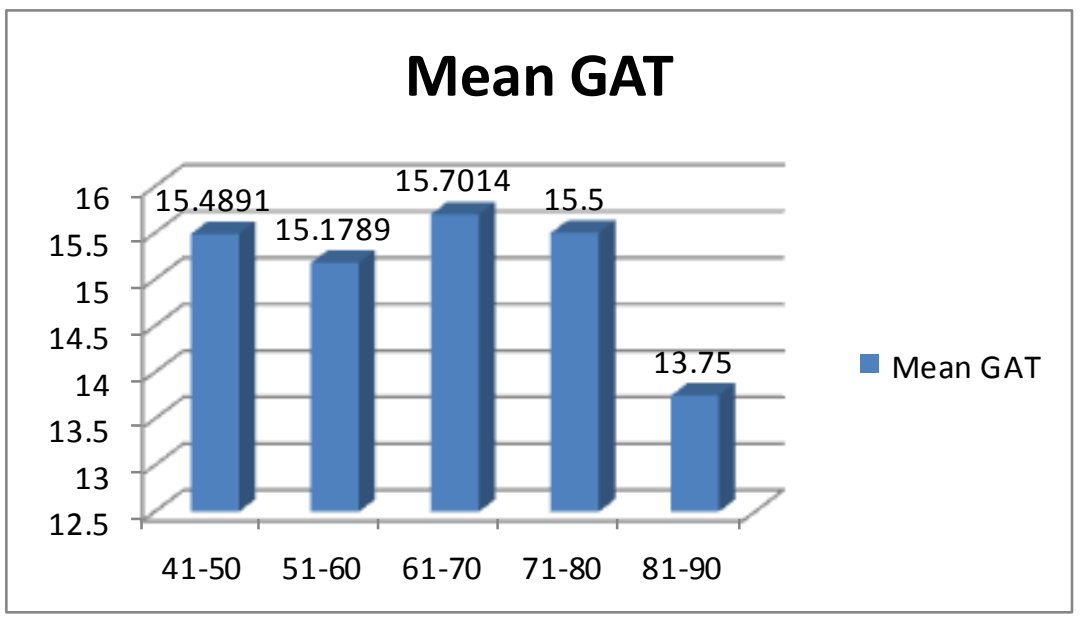

GRAPH 2: MEAN IOP VALUES FOR GAT IN DIFFERENT AGE GROUPS 
The mean GAT IOP values were found to be high in the age group of $61-70$ years which was $15.7 \pm 7.57 \mathrm{~m} \mathrm{Hg}$. The least was $13.75 \pm 9.10 \mathrm{~mm} \mathrm{Hg}$ was in the age group $81-90$ years.

Table 3: Mean IOP values for RBT in different age groups

\begin{tabular}{|c|c|c|c|c|}
\hline Age group & $\mathbf{N}$ & Mean RBT & Std. dev & Std. error \\
\hline $\mathbf{4 1 - 5 0}$ & 368 & 16.2473 & 6.97846 & .36378 \\
\hline $\mathbf{5 1 - 6 0}$ & 246 & 15.6707 & 5.34535 & .34081 \\
\hline $\mathbf{6 1 - 7 0}$ & 144 & 16.0972 & 7.99591 & .66633 \\
\hline $\mathbf{7 1 - 8 0}$ & 56 & 15.7679 & 8.67597 & 1.15937 \\
\hline $\mathbf{8 1 - 9 0}$ & 4 & 14.0000 & 9.27362 & 4.63681 \\
\hline Total & 818 & 16.0037 & 6.86315 & .23996 \\
\hline
\end{tabular}

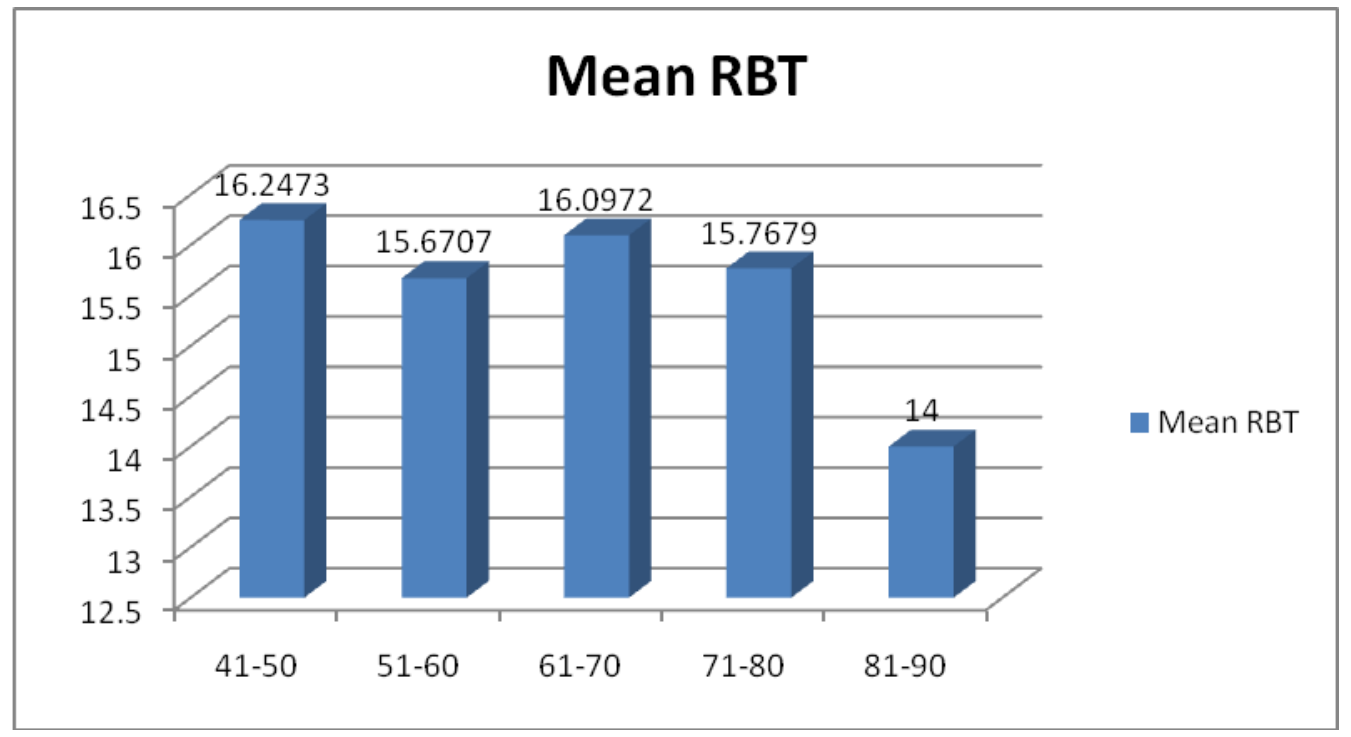

\section{GRAPH 3: MEAN IOP VALUES FOR RBT IN DIFFERENT AGE GROUPS}

The highest mean RBT value was $16 \pm 0.9 \mathrm{~mm} \mathrm{Hg}$ in the age group $61-70$ years. The least value was $14 \pm 6.8 \mathrm{~mm}$ $\mathrm{Hg}$ in the 81-90 years age group.

It is noted that the IOP values are increasing with increase in age from the above two tables. The less IOP values in the 71-90 years age group may be due to insufficient sample size for comparision.

Table 4: Mean CCT values in different age groups

\begin{tabular}{|c|c|c|c|c|}
\hline Age group & $\mathbf{N}$ & CCT & Std. dev & Std. error \\
\hline $\mathbf{4 1 - 5 0}$ & 368 & 530.5435 & 47.43190 & 2.47256 \\
\hline $\mathbf{5 1 - 6 0}$ & 246 & 525.0285 & 54.04574 & 3.44583 \\
\hline $\mathbf{6 1 - 7 0}$ & 144 & 500.4306 & 123.27731 & 10.27311 \\
\hline $\mathbf{7 1 - 8 0}$ & 56 & 484.2143 & 157.03650 & 20.98489 \\
\hline $\mathbf{8 1 - 9 0}$ & 4 & 520.0000 & 14.69694 & 7.34847 \\
\hline Total & 818 & 520.3606 & 80.12668 & 2.80156 \\
\hline
\end{tabular}


The mean highest CCT value was $530.54 \pm 47.43 \mu \mathrm{m}$ in the age group of $41-50$ years. From the above table it can be noted that as the age increased the CCT value decreases except for 81-90 years age group. This might be due to less number of eyes in that age group.

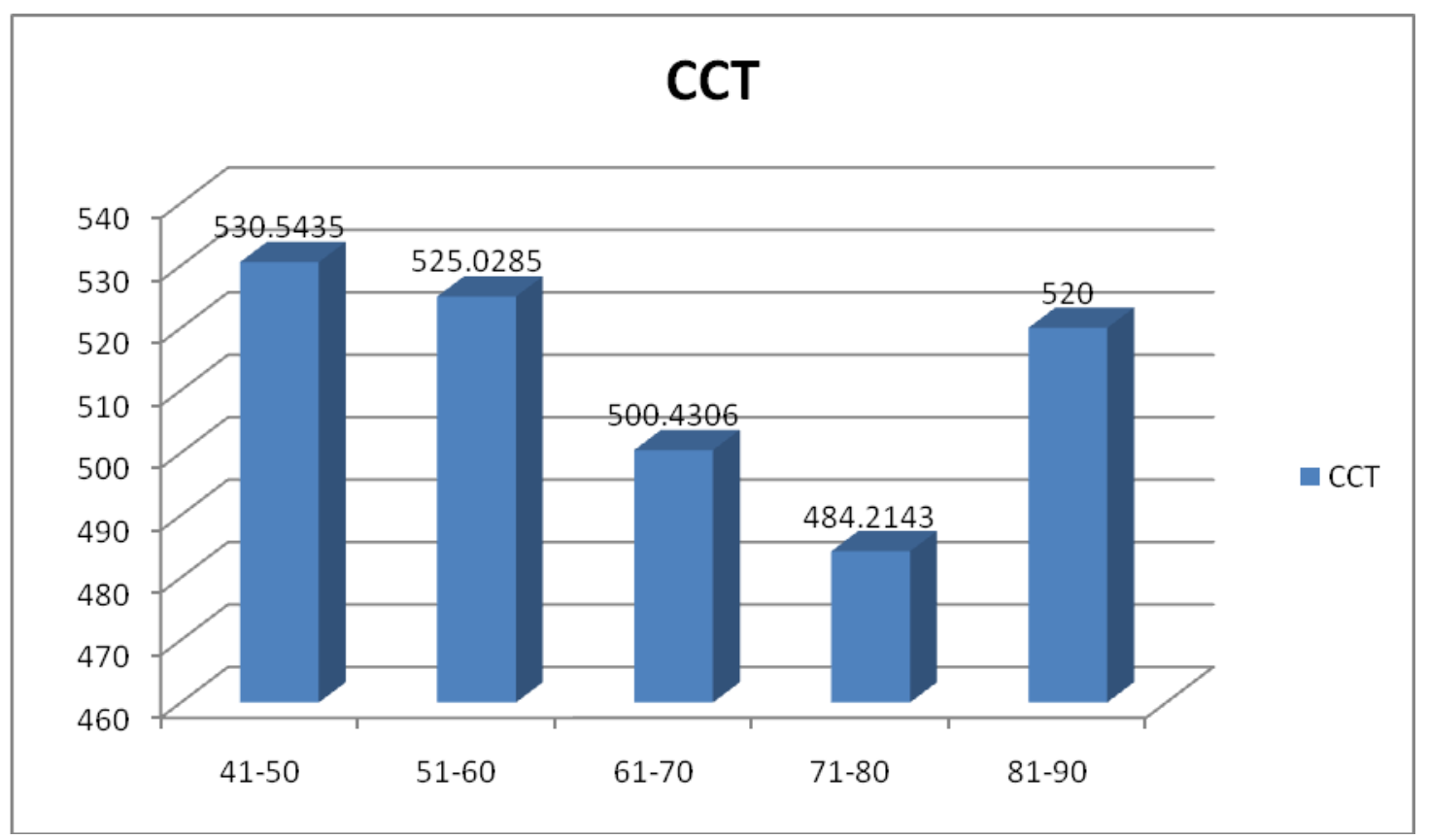

GRAPH 4: CCT DISTRIBUTION IN AGE GROUPS

Classification of the control group and glaucoma group according to CCT

The eyes were divided into two groups according to CCT. In the control group, there were 281 eyes with CCT less than $530 \mu \mathrm{m}$ and in glaucoma group there were 75 eyes.

CCT $\geq 531 \mu \mathrm{m}$ were found in 317 eyes in control group and 124 eyes in glaucoma group. A total of 356 eyes had $\mathrm{CCT} \leq 530 \mu \mathrm{m}$ and 441 eyes had $\mathrm{CCT} \geq 531 \mu \mathrm{m}$.

Table 5: Group classification according to CCT

\begin{tabular}{|c|c|c|c|}
\hline CCT & Control & Glaucoma & Percentage \\
\hline$<530 \mu$ & 281 & 75 & $44.7 \%$ \\
\hline$>531 \mu$ & 317 & 124 & $\mathbf{5 5 . 3 \%}$ \\
\hline Total & $\mathbf{5 9 8}$ & 199 & $\mathbf{1 0 0 \%}$ \\
\hline
\end{tabular}

Table 6: IOP measured by GAT and Rebound tonometer and CCT in normal patients

\begin{tabular}{|c|c|c|c|c|}
\hline IOP & Min & Max & Mean & SD \\
\hline RBT & 9 & 23 & 14.81 & \pm 2.81 \\
\hline GAT & 8 & 23 & 14.47 & \pm 2.98 \\
\hline CCT & 457 & 626 & 530.20 & \pm 25.63 \\
\hline
\end{tabular}

Table 7: IOP measured by GAT and Rebound tonometer and CCT in glaucoma patients and Glaucoma

\begin{tabular}{|l|c|c|c|c|}
\hline IOP & Min & Max & Mean & SD \\
\hline RBT & 8 & 56 & 20.55 & \pm 8.74 \\
\hline GAT & 8 & 50 & 19.88 & \pm 8.74 \\
\hline CCT & 443 & 675 & 533.66 & \pm 28.90 \\
\hline
\end{tabular}

The mean IOP value obtained were $14.81 \pm 2.81 \mathrm{~mm} \mathrm{Hg}$ for RBT ranging between $9 \mathrm{~mm} \mathrm{Hg}$ to $23 \mathrm{~mm}$ $\mathrm{Hg}$. The mean IOP value for GAT was $14.47 \pm 2.98 \mathrm{~mm} \mathrm{Hg}$ ranging between $8 \mathrm{~mm} \mathrm{Hg}$ to $23 \mathrm{~mm} \mathrm{Hg}$. The mean 
CCT value was $530.20 \pm 25.63 \mu \mathrm{m}$ ranging between $457 \mu \mathrm{m}$ to $626 \mu \mathrm{m}$. The difference between RBT and GAT was $0.54 \mathrm{~mm} \mathrm{Hg}$.

In the glaucoma group, the minimum values of RBT, GAT and CCT were $8 \mathrm{~mm} \mathrm{Hg}, 8 \mathrm{~mm} \mathrm{Hg}$ and 443 $\mu \mathrm{m}$ respectively. The maximum values obtained using RBT, GAT and pachymetry were $56 \mathrm{~mm} \mathrm{Hg}, 50 \mathrm{~mm} \mathrm{Hg}$ and $675 \mu \mathrm{m}$ respectively. The mean IOP value obtained were $20.55 \pm 8.74 \mathrm{~mm} \mathrm{Hg}$ for RBT and $19.88 \pm 8.74 \mathrm{~mm}$ $\mathrm{Hg}$. the mean CCT value was $533.66 \pm 28.90 \mu \mathrm{m}$. The difference between RBT and GAT was $1.67 \mathrm{~mm} \mathrm{Hg}$.

The Mean IOP Values Of RBT And GAT In Eyes Having CCT < 530 $\mu \mathrm{m}$ In The Control Group.

Table 8: IOP distribution in control group with CCT $<530 \mu \mathrm{m}$

\begin{tabular}{|c|c|c|c|c|c|}
\hline Tonometers & $\mathbf{N}$ & Mean $(\mathbf{m m} \mathbf{H g})$ & Std. Deviation & \multirow{2}{*}{ P value } & GAT-RBT \\
\cline { 1 - 3 } GAT & $\mathbf{2 8 0}$ & 14.3571 & 2.83367 & 0.74 & -0.42 \\
\hline RBT & $\mathbf{2 8 0}$ & 14.7815 & 2.90696 & \\
\hline
\end{tabular}

The Mean IOP Values Of RBT And GAT In Eyes Having CCT > 530 $\mu \mathrm{m}$ In The Control Group.

Table 9: IOP distribution in control group with CCT > 530 $\mu \mathrm{m}$

\begin{tabular}{|c|c|c|c|c|c|}
\hline Tonometers & $\mathbf{N}$ & Mean $(\mathbf{m m}$ Hg) & Std. Deviation & P value & \multirow{2}{*}{ GAT- RBT } \\
\hline GAT & $\mathbf{4 4 1}$ & 16.3888 & 5.93462 & 0.81 & 0.081 \\
\hline RBT & $\mathbf{4 4 1}$ & 16.3078 & 5.41992 & 0.081 \\
\hline
\end{tabular}

The mean IOP value for GAT was $14.35 \pm 2.83 \mathrm{~mm} \mathrm{Hg}$ and for RBT was $14.78 \pm 2.90 \mathrm{~mm} \mathrm{Hg}$ in the eyes having $\mathrm{CCT} \leq 530 \mu \mathrm{m}$. The RBT values were found to be more than the GAT values.

The mean difference between RBT and GAT values was $0.4 \pm 3.9 \mathrm{~mm}$ Hg which was not statistically significant ( $\mathrm{p}$ value -0.74 ).

The mean IOP value for RBT was $16.3 \pm 5.41 \mathrm{~mm} \mathrm{Hg}$ and for GAT was $16.3 \pm 5.9 \mathrm{~mm} \mathrm{Hg}$ for CCT values $\geq$ $531 \mu \mathrm{m}$. The IOP values were similar in both the groups.

The difference between RBT and GAT was $0.8 \pm 7.10 \mathrm{~mm}$ Hg which was not statistically significant (p value $0.81)$.

The Mean IOP Values Of RBT And GAT In Eyes Having CCT >531 $\mu \mathrm{m}$ In Glaucoma Group.

Table 10: IOP distribution in glaucoma group with CCT > 530 $\mu \mathrm{m}$

\begin{tabular}{|c|c|c|c|c|c|}
\hline Tonometers & No. & Mean (mm Hg) & Std. Deviation & \multirow{2}{*}{ P value } & \multirow{2}{*}{ GAT- RBT } \\
\hline GAT & $\mathbf{1 2 4}$ & 21.0242 & 8.42418 & 0.93 & 0.967 \\
\hline RBT & $\mathbf{1 2 4}$ & 20.0565 & 8.19211 & 0.967 \\
\hline
\end{tabular}

The Mean IOP Values Of RBT And GAT In Eyes Having CCT < 530 $\mu \mathrm{m}$ In Glaucoma Group.

Table 11: IOP distribution in glaucoma group with CCT $<530 \mu \mathrm{m}$.

\begin{tabular}{|c|c|c|c|c|c|}
\hline Tonometers & No. & Mean(mm Hg) & Std. Deviation & \multirow{2}{*}{ P value } & GAT-RBT \\
\hline GAT & $\mathbf{7 5}$ & 18.0133 & 7.29401 & 0.79 & -0.36 \\
\hline RBT & $\mathbf{7 5}$ & 18.3733 & 9.59416 & \\
\hline
\end{tabular}

The mean IOP value for RBT was $21 \pm 8.42 \mathrm{mmm} \mathrm{Hg}$ and for GAT was $20.05 \pm 8.19 \mathrm{~mm} \mathrm{Hg}$ for CCT values $\leq$ $531 \mu \mathrm{m}$. The IOP value of RBT was more than GAT.

The difference between RBT and GAT IOP values was $0.9 \pm 11.51 \mathrm{~mm} \mathrm{Hg}$. the difference between the two instruments was not statistically significant ( $\mathrm{p}$ value -0.93 ).

The mean IOP value for GAT was $18.0 \pm 7.29 \mathrm{~mm} \mathrm{Hg}$ and for RBT was $18.3 \pm 9.59 \mathrm{~mm} \mathrm{Hg}$ for eyes having CCT value less than $530 \mu \mathrm{m}$. 
The difference between RBT and GAT value was $0.3 \mathrm{~mm} \mathrm{Hg}$ which was statistically not significant ( $\mathrm{p}$ value 0.79 ).

It was also noted that as the CCT increased the IOP also increased.

The overall IOP values of both RBT and GAT were found to increase with increase in CCT and this relation was found to be statistically significant (P value -0.00$)$. But the correlation between IOP values of RBT and GAT for CCT of $\langle 530 \mu$ and $>530 \mu$ were not statistically significant.

GRAPH 5: SCATTER PLOT OF CCT AGAINST RBT AND GAT

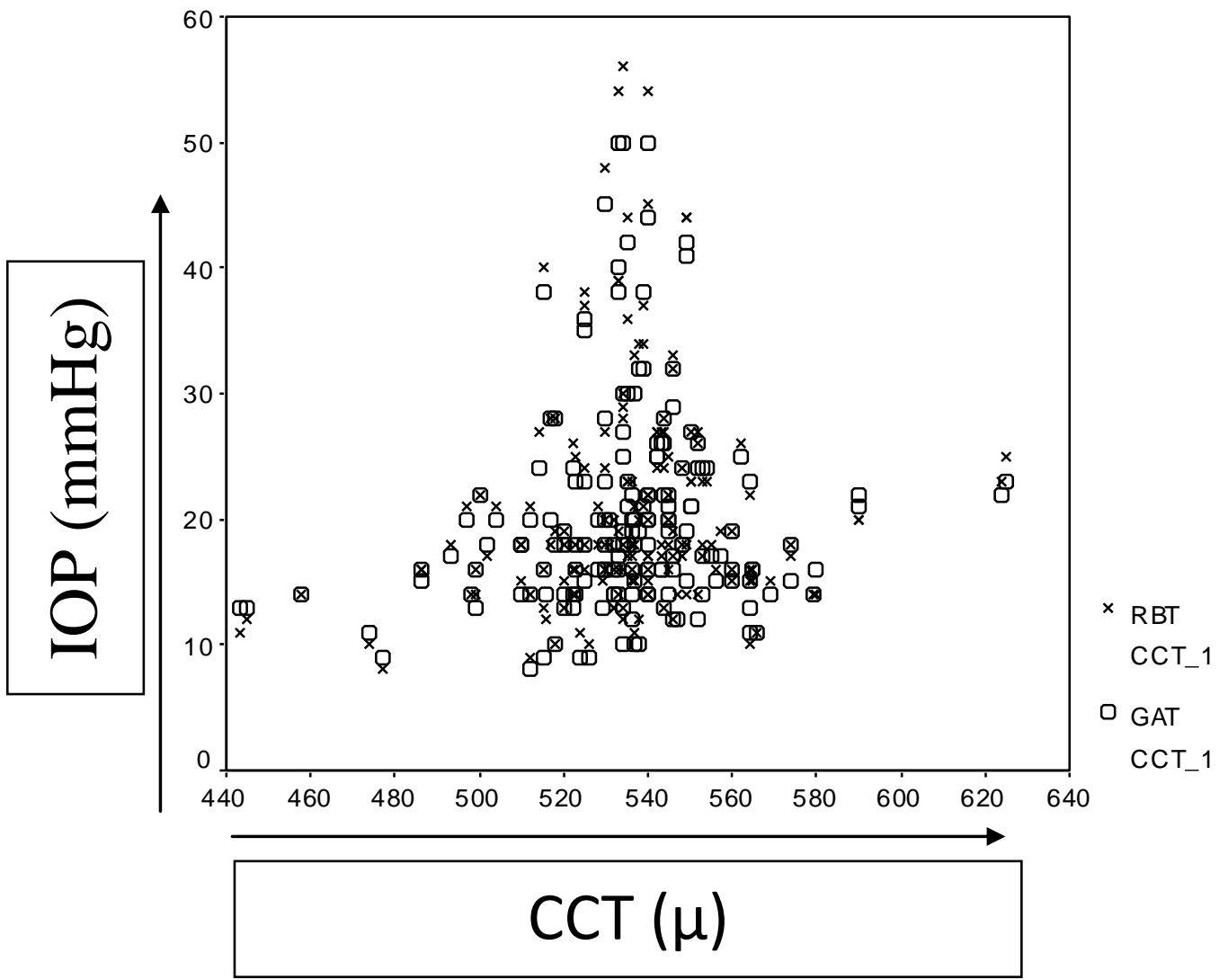

From the above scatter plot it can be noted that there is clustering of points representing IOP values for CCT values ranging between 520 to $560 \mu \mathrm{m}$

\section{Discussion}

Goldmann applanation tonometry is today the gold standard for IOP measurement. However, since its early days it has been known that readings can be distorted by several physical properties of the eye such as corneal curvature, axial length, and central corneal thickness. Goldmann himself admitted that the physical assumptions on which his tonometer was based were calculated for a central corneal thickness of $500 \mu \mathrm{m}$, and that readings for corneas thicker or thinner than this value could be less precise. Several studies subsequently have corroborated this limitation, and differences in corneal thickness have proven to be one of the main sources of error in applanation tonometry measurements.

Several new tonometers designed to avoid some of the limitations of conventional tonometry have appeared on the market. One of them being rebound tonometer.

This study included a total of 409 patients. A total 797 eyes were examined. Out of these, 199 eyes of 101 patients were included in the glaucoma group. There were 166 eyes with open angle glaucoma and glaucoma suspects and 33 eyes with closed angle glaucoma.

The present study can be compared with a similar studies by Jose Martinez et al and Brusini et al. Jose Martinez et al examined 146 eyes out of which 67 patients had POAG and 34 had ocular hypertension.

In the study done by Brusini et al, 178 patients with POAG were included in the study. 
Table 12: Comparison of participants in different studies - Glaucoma patients

\begin{tabular}{|c|c|c|c|c|c|c|}
\hline Study & N & Mean Age & $\begin{array}{c}\text { Mean RBT } \\
(\mathbf{m m ~ H g})\end{array}$ & $\begin{array}{c}\text { Mean GAT } \\
(\mathbf{m m ~ H g})\end{array}$ & Mean CCT( $\boldsymbol{\mu m})$ & RBT-GAT \\
\hline $\begin{array}{c}\text { Present study } \\
\text { Jose Martinez } \\
\text { et al }\end{array}$ & 101 & $56 \pm 11.73$ & $20.55 \pm 8.74$ & $19.88 \pm 8.13$ & $533.66 \pm 28.90$ & 1.67 \\
\hline $\begin{array}{c}\text { Paolo Brusini } \\
\text { et al }\end{array}$ & 178 & $67 \pm 14.4$ & $20.5 \pm 5.3$ & $19.1 \pm 5.1$ & $550 \pm 43.2$ & $1.4 \pm 2.7$ \\
\hline
\end{tabular}

From the above table it can be seen that the number of participants in different studies ranged between 101 to 178 people. Our sample size is comparable to Jose Martinez et al.

In the present study, age ranged between 40 and 82 years. The age group in Brusini et al study ranged between 30 to 93 years.

In Martinez et al study, the IOP values of RBT were more than GAT in both CCT groups. But the mean IOP value for RBT was less compared to GAT value in Brusini et al study. In the present study, the IOP values of RBT were more than GAT when CCT was less than $530 \mu \mathrm{m}$ and less than GAT values when CCT was more than $531 \mu \mathrm{m}$.

Table 13: Mean intraocular pressure values in different studies according to corneal thickness

\begin{tabular}{|c|c|c|c|c|}
\hline Study & Sample size (n) & $\operatorname{CCT}(\mu \mathrm{m})$ & Mean GAT(mm Hg) & Mean RBT(mm Hg) \\
\hline \multirow{2}{*}{ Present study } & \multirow{2}{*}{101} & $<530$ & $18.01 \pm 7.29$ & $18.37 \pm 9.59$ \\
\hline & & $>531$ & $21.04 \pm 8.42$ & $20.05 \pm 8.19$ \\
\hline \multirow{2}{*}{ Martinez et al } & \multirow{2}{*}{146} & $<531$ & $17.4 \pm 5.6$ & $17.8 \pm 5.2$ \\
\hline & & $>565$ & $19.9 \pm 4.1$ & $21.4 \pm 4.6$ \\
\hline
\end{tabular}

It was also noted that in both groups the IOP value increased with increase in CCT.

The mean difference between RBT and GAT values in Martinez et al study was $1.4 \pm 2.7 \mathrm{mmHg}$. The P value was 0.218 .

In the present study the mean difference between RBT and GAT (GAT-RBT) was $0.96 \pm 11.51 \mathrm{~mm} \mathrm{Hg}$ in CCT $\geq$ $531 \mu \mathrm{m}$ and $0.36 \pm 11.7 \mathrm{~mm} \mathrm{Hg}$ in CCT group of $\leq 530 \mu \mathrm{m}$. The P value was 0.351 and 0.792 respectively. In both the groups the difference between the instruments was not statistically significant.

Table 14: Comparison of Participants in Different Studies - Control (Normal) Patients

\begin{tabular}{|c|c|c|c|c|c|c|}
\hline Study & $\mathbf{N}$ & $\begin{array}{c}\text { Mean } \\
\text { Age(years })\end{array}$ & $\begin{array}{c}\text { Mean RBT } \\
(\mathbf{m m} \mathbf{H g})\end{array}$ & $\begin{array}{c}\text { Mean GAT } \\
(\mathbf{m m} \mathbf{H g})\end{array}$ & $\begin{array}{c}\text { Mean } \\
\mathbf{C C T}(\boldsymbol{\mu m})\end{array}$ & RBT-GAT \\
\hline Present study & 308 & $53.44 \pm 9.9$ & $20.55 \pm 8.74$ & $19.88 \pm 8.13$ & $533.66 \pm 28.90$ & 1.67 \\
\hline $\begin{array}{c}\text { M E Iliev } \\
\text { et al }\end{array}$ & 28 & $50.38 \pm 23.58$ & $20.5 \pm 5.3$ & $19.1 \pm 5.1$ & $550 \pm 43.2$ & $1.4 \pm 2.7$ \\
\hline $\begin{array}{c}\text { Nima Pakrou et } \\
\text { al }\end{array}$ & 153 & $59.6 \pm 21.2$ & $18.4 \pm 5.2$ & $19.4 \pm 5.4$ & $552 \pm 39$ & $1.0 \pm 3.5$ \\
\hline
\end{tabular}

From the above table it is seen that the sample size in different study groups ranged between 28 to 308 patients. The present study had the maximum number of participants. The age of the patients ranged between 40-82 years.

The mean GAT values of all the three studies are similar. In all the three studies the IOP values increased with increase in CCT. The mean CCT value of the present study was less compared to the other two studies.

Only the patients who belonged to group 1 in the M E Iliev study are taken for comparison with the present study as the group 2 of M E Iliev study includes postoperative patients which comes under the exclusion criteria of the present study.

In the Nima Pakrou study, the p value obtained was 0.09 which was not statistically significant. The author has mentioned that the relation of RBT with CCT was statistically significant (P value- 0.05, 0.01). but GAT was found not be affected much by CCT value(P value -0.25$)$.

In ME Iliev study, the author has used regression analysis for analysis of data. RBT values were found to increase with increase in CCT. A small but statistically significant difference was noted between GAT and RBT. In the present study, the difference between RBT and GAT ranged between 0.42 to 0.0811 in CCT of $\leq 530 \mu \mathrm{m}$ group and CCT of $\geq 531 \mu \mathrm{m}$ group respectively ( $\mathrm{P}$ value -0.074 and 0.811 ).

In conclusion, the present study correlated the rebound tonometer values with Goldmann applanation values and found that there was no statistically significant difference in the measurements obtained by the two instruments. It was also noted that when central cornea thickness was less, RBT recorded higher values than GAT but the difference was not statistically significant. When CCT increased, the IOP values of both the instruments 
increased but GAT recorded higher values than RBT. The difference between their IOP values was again not statistically significant.

\section{LIMITATIONS OF THE STUDY}

Post operatives cases were excluded from the study and all the secondary glaucomas were excluded from the study. This limits the knowledge about variations in the IOP values of RBT and GAT and influence of CCT on them.

The population of the study comprised only those patients who visited the outpatient department of JSS hospital and did not cover people from different region to comment on the variation of CCT, RBT and GAT in them.

Other corneal compounding factors such as corneal hysteresis, corneal resistance factor, corneal curvature affecting IOP measurement are not evaluated and other tonometers are not compared.

The IOP values in the present study have not been corrected for the CCT values according to the available correction factor nomograms

\section{CONCLUSION}

Central corneal thickness influences the intraocular pressure recordings of both rebound tonometer and Goldmann applanation tonometer and thicker corneas yield higher intraocular pressure values. The Rebound tonometer gave higher readings in comparison to Goldmann applanation tonometer in thinner corneas and lesser readings in thicker corneas. There was no statistically significant difference between the two tonometers and they showed good correlation in relation to the central corneal thickness.

Therefore correction for central corneal thickness will provide a more accurate IOP reading and aid in the proper management of glaucoma cases. Further studies are needed taking into consideration different values of CCT to derive an accurate correction factor.

\section{REFERENCES}

[1]. Ehler N, Bramsen T, Sperling S., Applanation tonometry and central corneal thickness, Acta Ophthal Copenh 1975;53:34-43.

[2]. JoAnn A. Giovani, Simon K. Law, Pearls of glaucoma management, pg79-80, $1^{\text {st }}$ edition, Springer-Verlag Berlin Heidelberg 2010.

[3]. Danias J, Kontiola AI, Filippopoulos T, Mittag T. Method for the noninvasive measurement of intraocular pressure in mice. Invest Ophthalmol Vis Sci 2003;44:1138-41.

[4]. Krishnadas J. Prevalence of Glaucoma in India and the World. Tamil Nadu Journal of Ophthalmology, Dec 2009 : Vol. 47; issue 4: 13-6.

[5]. Shields MB. R, Allingham. Textbook of glaucoma, in: intra ocular pressure and tonometry. An overview of glaucoma, $5^{\text {th }}$ edition. Lippincott Williams and Wilkins.

[6]. Becker Shaffer's diagnosis and therapy of glaucoma, chapter: Introduction and classification of glaucoma, pg4-6,8 ${ }^{\text {th }}$ edition, Elsivier, Mosby.

[7]. Francois J, Victoria-Troncoso V: Mucopolysaccharide and pathogenesis of cortisone glaucoma, Klin Mbl Augenheilk;165:5,1974.

[8]. Zimmerman LE: The outflow problem in normal and pathologic eyes, Trans Am Acad Ophthalmol Otolaryngol 70:767, 1966.

[9]. Rohen JW: Fine structural changes in the trabecular meshwork of the human eye in different forms of glaucoma, Klin Monatsbl Augenheilkd 163:401, 1973.

[10]. Lütjen-Drecoll E, Shimiza T, Rohrback M: Quantitative analysis of plaque material in the inner and outer wall of Schlemm's canal in normal and glaucomatous eyes, Exp Eye Res 42:443, 1986.

[11]. Johnson MC, Ethier CR, Kamm RD: The flow of aqueous humor through microporous filters, Invest Ophthalmol Vis Sci 27:92, 1986.

[12]. Alvarado J, Murphy C, Juster R: Trabecular cellularity in primary open-angle glaucoma and nonglaucomatous normals, Ophthalmology 91;564:1984.

[13]. Mosely H, Grierson I, Lee WR: Mathematical modeling of aqueous humour outflow from the eye through the pores in the lining endothelium of Schlemm's canal, Clin Phys Physiol Meas 4;47:1983.

[14]. Tripathi RC: Ultrastructure of the trabecular wall of Schlemm's canal (a study of normotensive and chronic simple glaucomatous eyes), Trans Ophthalmol Soc UK 89;449:1969.

[15]. Rohen JW, van der Zyphen E: The phagocytic activity of the trabecular meshwork endothelium: an electron-microscopic study of the vervet (Cercopithecus aethiops), Graefes Arch Clin Exp.

[16]. Tamm ER, et al: Nerve endings with structural characteristics of mechanoreceptors in the human scleral spur, Invest Ophthalmol Vis Sci 35;1157:1994.

[17]. Becker Shaffer's diagnosis and therapy of glaucoma, chapter: Introduction and classification of glaucoma, pg.189-95; $8^{\text {th }}$ edition: Elsivier, Mosby.

[18]. Clemmesen V, Luntz MH: Lens thickness and angle-closure glaucoma: a comparative oculometric study in South African negroes and Danes, Acta Ophthalmol (Copenh) 54;193: 1976.

[19]. Tornquist R: Peripheral chamber depth in shallow anterior chamber, Br J Ophthalmol 43;169:1959.

[20]. Alsbirk PH: Anterior chamber depth and primary angle-closure glaucoma. I. An epidemiologic study in Greenland Eskimos, Acta Ophthalmol (Copenh) 53;89:1975.

[21]. Lowe RF, Clark BAJ: Posterior corneal curvature correlations in normal eyes and in eyes involved with primary angle-closure glaucoma, Br J Ophthalmol 57;464: 1973.

[22]. Lowe RF, Clark BAJ: Radius of curvature of the anterior lens surface, Br J Ophthalmol 57;471:1973.

[23]. Robert Stamper, IOP: Instruments to measure IOP, chapter 9, pearls of glaucoma management, $1^{\text {st }}$ edition, Pg:79-81,SpringerVerlag Berlin Heidelberg 2010.

[24]. Argus WA. Ocular hypertension and central corneal thickness. Ophthalmology 1995;102:1810 -2. 
[25]. Bruce M. Shields et al, Introcular pressure and tonometry, section 1, chapter 2, Shield's textbook of glaucoma $5^{\text {th }}$ edition, Pg:31-45. Lippincot Williams and Wilkins.

[26]. Goldmann Applanation Tonometer, instruction manual, Haag-Streit International.

[27]. Dawn EC Roberts, comparison of iCare tonometer with pulsair and Tonopen in domiciliary work, optometry in practice vol.6 (2005)33-39

[28]. Duke Elder S. refraction and Ophthalmic optics, Vol 5, system of Ophthalmlogy.

[29]. Thorton SP, Garderner SK, surgical instruments used in refractive keratotomy, refractive keratotomy for myopia and astigmatism, St. Louis, Mosby 1992

[30]. Miller D, Thal EH, Ophthalmic instrumentation, Yanoff M and Duker JS, Ophthalmology, $2^{\text {nd }}$ edition, Mosby.

[31]. Volkan Y, Kaufmann SC, corneal thickness measurements with orbscan topography system and ultrasonic pachymetry, J. cataract refract surg, 1997; vol 23: 345-50.

[32]. James D. Brandt, Central Corneal Thickness. Chapter 10. Pearls to Glaucoma Management. $1^{\text {st }}$ Edition. Pg: 87-91. Springer-Verlag Berlin Heidelberg 2010.

[33]. Jose M Martinez-de-le Casa, Julian Gracia-Feijoo, Ana Fernandez-Vidal. Ocular response analyzer versus Goldmann Applanation tonometer for IOP measurement. Investigative ophthalmology and visual science. Oct-2006, vol.47;no.10:pg.4410-14.

[34]. Kontiola AI. A new induction-based impact method for measuring intraocular pressure. Acta Ophthalmol Scand. 2000;78:142-145.

[35]. Kontiola AI, Goldblum D, Mittag T, et al. The induction/impact tonometer: a new instrument to measure intraocular pressure in the rat. Exp Eye Res. 2001;73:781-785.

[36]. Kontiola A, Puska P. Measuring intraocular pressure with the Pulsair 3000 and Rebound tonometers in elderly patients without an anesthetic. Graefes Arch Clin Exp Ophthalmol. 2004;242: 3-7.

[37]. Nicolas F, Dorothee L, Jens F. Correlation between central corneal thickness, applanation tonometry, and direct intracameral IOP readings. Br J Ophthalmol 2001;85:85-87

[38]. Jose M. Martinez-de-la-Casa et al. Effect of Corneal Thickness on Dynamic Contour, Rebound, and Goldmann Tonometry. J Ophthalmology. American Academy of Ophthalmology. 2006;113: 2156-2162.

[39]. M E Iliev, D Goldblum, K Katsoulis, C Amstutz, B Frueh.Comparison of rebound tonometry with Goldmann applanation tonometry and correlation with central corneal thickness. Br J Ophthalmol 2006;90:833-835. doi: 10.1136/bjo.2005.089870.

[40]. Herndon LW, Choudhri SA, Cox T, et al. Central corneal thickness in normal, glaucomatous, and ocular hypertensive eyes. Arch Ophthalmol 1997;115:1137-41.

[41]. Paolo Brusini, Maria LS, Marco Z, Claudia T, Lucia P. Comparison of ICare Tonomseter with Goldmann Applanation Tonometer in Glaucoma Patients. J Glaucoma 2006;15:213-217.

[42]. Nima P, Tim G, Richard M, John L et al.Clinical Comparison of the Icare Tonometer and Goldmann Applanation Tonometry. J Glaucoma 2008;17:43-47.

[43]. Makoto N, Urtogtah D, Yasuko T, et al. Agreement of Rebound Tonometer in Measuring Intraocular Pressure With Three Types of Applanation Tonometers. Am J Ophthalmol 2006;142:332-334.

[44]. Jose M. Martinez-de-la-Casa, Julian GF, et al. Comparison of Rebound Tonometer and Goldmann Handheld Applanation Tonometer in Congenital Glaucoma. J Glaucoma 2009;18:49-5.

[45]. Wan-sang Chui, Andrew L, Davie C et al.The Influence of Corneal Properties on Rebound Tonometry. J Ophthalmology. by the American Academy of Ophthalmology.2008;115:80-84.

[46]. Guy R, Alon H, Brent S, et al. Goldmann Applanation Tonometry and Dynamic Contour Tonometry are not Correlated With Central Corneal Thickness in Primary Open Angle Glaucoma. J Glaucoma 2011;20:282-286

[47]. Kirsten EH, David CP, Shivani A, et al. Diurnal Variation of Central Corneal Thickness and Goldmann Applanation Tonometry Estimates of Intraocular Pressure. J Glaucoma 2007;16:29-35.

[48]. Daniel H. W. Su et al, Diabetes, Hyperglycemia, and Central Corneal Thickness, The Singapore Malay Eye Study J Ophthalmology. by the American Academy of Ophthalmology. 2008;115:964-968.

[49]. James D B, Julia AB, Michael AK, et al. The Ocular Hypertension Treatment Study (OHTS) Group. Central Corneal Thickness in the Ocular Hypertension Treatment Study (OHTS), J Ophthalmology. American Academy of Ophthalmology. 2001;108:17791788.

[50]. Vinay N, Jost B. Jonas, Ajit S, et al. Central Corneal Thickness and Its Association with Ocular and General Parameters in Indians: The Central India Eye and Medical Study. J Ophthalmology. American Academy of Ophthalmology. 2010;117:705-710.

[51]. Dandan W, Wenyong H, Yuetao li, et al .Intraocular pressure, Central Corneal thickness, and Glaucoma in chinese adults: the Liwan eye study. Am J Ophthalmol 2011;152:454-462.

[52]. Yukinori H, Naofumi H, Toshiaki K et al. The Influence of Central Corneal Thickness and Corneal Curvature Radius on the Intraocular Pressure as Measured By Different Tonometers: Noncontact and Goldmann Applanation Tonometers. J Glaucoma 2008; 17:619-625

[53]. Sanjay A, Ashmita C, David KW et al. Evaluation of the ICare Rebound Tonometer as a Home Intraocular Pressure Monitoring Device. J Glaucoma 2011;20:74-79.

[54]. Afsun S, Hikmet B, Nilgun Y. The Influence of Central Corneal Thickness and Corneal Curvature on Intraocular Pressure Measured by Tono-Pen and Rebound Tonometer in Children. J Glaucoma 2008;17:57-61

[55]. Shih CY et al, Clinical significance of central corneal thickness in the management of glaucoma, Arch Ophthalmol 2004: 122; $1270-1$. 